\title{
P005: Effect of improvement activity for decreasing catheter related bloodstream infection
}

\author{
MN Kim ${ }^{1 *}, \mathrm{NH}$ Cho ${ }^{1}$, YG Song ${ }^{2}, \mathrm{JH}$ Yoon ${ }^{2}$ \\ From 2nd International Conference on Prevention and Infection Control (ICPIC 2013) \\ Geneva, Switzerland. 25-28 June 2013
}

\begin{abstract}
Introduction
Insertion of central venous catheter is essential procedure for treatment of critical patient, but if this procedure is increased, bloodstream infection (BSI) can be increased. But through fulfillment of practice guideline, Catheter related Bloodstream Infection (CRBSI) can be fully prevented, and many hospitals try to decrease BSI like "0" percent.
\end{abstract}

\section{Objectives}

In Intensive care unit (ICU) of this hospital, during the year 2010, BSI was 5.8/1000 device day but, it was increased like 12.2/1000 device day in April 2011. Therefore we started improvement activity to decrease BSI.

\section{Methods}

We carried out improvement activities for three times for the patients who were inserted with central venous catheter from April 2011 to October 2012. First (2011.04-2011.07), 1) Prevention protocol review about BSI and sharing the protocol with relevant department, 2) SMS feedback to medical team about checklists and results with Maximum sterile barrier precaution, 3) Weekly experts (ID physician and IC nurse) rounding to ICU and CCU, and checking condition of central venous catheter. Second (2012.05), 1) Continuing previous improvement activity, 2) Sharing the protocol for sampling method of blood culture with relevant department, 3) Writing the name who inserted central venous catheter at the insertion site. Third (2012.08-2012.10), 1) Notifying above protocols periodically, 2) Changing antiseptic from betadine to $2 \%$ alcoholic chlorhexidine gluconate solution since July 2012 when the commercial product was available.

\section{Results}

When we compared CRBSI from first period (2011.04 06) to third period (2012.08 10), CRBSI was decreased as $45 \%$ from $10.1 / 1000$ device day to $5.6 / 1000$ device day in ICU and as $50 \%$ from 6.0 to 3.0 in whole wards

\section{Conclusion}

We performed three improvement activities for decreasing CRBSI, we can confirm the effects of those activities. For decreasing CRBSI, continuous improvement activities are needed than temporary activities, and monitoring system which can monitor insertion practice of central venous catheter is also needed. After this, if we develop more effective system which can monitor the process, we can make larger effect.

\section{Disclosure of interest}

None declared.

\section{Author details}

${ }^{1}$ Department of Infection Control, Gangnam Severance Hospital, Seoul, Korea, Democratic People's Republic Of. ${ }^{2}$ Department of Infectious disease, Gangnam Severance Hospital, Seoul, Korea, Democratic People's Republic Of.

Published: 20 June 2013

\section{doi:10.1186/2047-2994-2-S1-P5}

Cite this article as: Kim et al:: P005: Effect of improvement activity for decreasing catheter related bloodstream infection. Antimicrobial Resistance and Infection Control 2013 2(Suppl 1):P5.

'Department of Infection Control, Gangnam Severance Hospital, Seoul,

Korea, Democratic People's Republic Of

Full list of author information is available at the end of the article

(c) 2013 Kim et al; licensee BioMed Central Ltd. This is an Open Access article distributed under the terms of the Creative Commons 